\title{
Rem2 GTPase maintains survival of human embryonic stem cells as well as enhancing reprogramming by regulating $\mathrm{p} 53$ and cyclin $\mathrm{D}_{1}$
}

\author{
Michael J. Edel, ${ }^{1}$ Cristina Menchon, ${ }^{1}$ Sergio Menendez, ${ }^{1}$ Antonella Consiglio, ${ }^{1,5}$ Angel Raya, ${ }^{1,2,3,6}$ \\ and Juan Carlos Izpisua Belmonte ${ }^{1,3,4,7}$ \\ ${ }^{1}$ Center of Regenerative Medicine in Barcelona, 08003 Barcelona, Spain; ${ }^{2}$ Institució Catalana de Recerca i Estudis Avançats \\ (ICREA), 08010 Barcelona, Spain; ${ }^{3}$ Networking Center of Biomedical Research in Bioengineering, Biomaterials and \\ Nanomedicine (CIBER-BBN), 08003 Barcelona, Spain; ${ }^{4}$ Gene Expression Laboratory, Salk Institute for Biological Studies, \\ La Jolla, California 92037, USA
}

\begin{abstract}
Human pluripotent stem cells, such as embryonic stem cells (hESCs) and induced pluripotent stem cells (iPSCs), have the unique abilities of differentiation into any cell type of the organism (pluripotency) and indefinite selfrenewal. Here, we show that the Rem 2 GTPase, a suppressor of the p53 pathway, is up-regulated in hESCs and, by loss- and gain-of-function studies, that it is a major player in the maintenance of hESC self-renewal and pluripotency. We show that Rem 2 mediates the fibroblastic growth factor 2 (FGF2) signaling pathway to maintain proliferation of hESCs. We demonstrate that Rem 2 effects are mediated by suppressing the transcriptional activity of $p 53$ and cyclin $D_{1}$ to maintain survival of hESCs. Importantly, Rem2 does this by preventing protein degradation during DNA damage. Given that Rem2 maintains hESCs, we also show that it is as efficient as c-Myc by enhancing reprogramming of human somatic cells into iPSCs eightfold. Rem 2 does this by accelerating the cell cycle and protecting from apoptosis via its effects on cyclin $D_{1}$ expression/localization and suppression of p53 transcription. We show that the effects of Rem 2 on cyclin $D_{1}$ are independent of $p 53$ function. These results define the cell cycle and apoptosis as a rate-limiting step during the reprogramming phenomena. Our studies highlight the possibility of reprogramming somatic cells by imposing hESC-specific cell cycle features for making safer iPSCs for cell therapy use.
\end{abstract}

[Keywords: Rem2; cyclin D1; p53; reprogramming; self-renewal]

Supplemental material is available at http://www.genesdev.org.

Received October 20, 2009; revised version accepted February 3, 2010.

In recent years, the field of pluripotent human embryonic stem cells (hESCs), including the discovery of induced pluripotent stem cells (iPSCs), has moved rapidly in the direction of finding a safe application for clinical use, such as cell replacement therapy and modeling for drug discovery. However, relatively little has been done to advance our mechanistic insights into the properties of self-renewing hESCs, and even less is known about the mechanisms governing iPSC formation. A better understanding of the molecular mechanisms controlling pluripotency and self-renewal would be essential for the clinical translation of hESCs and iPSCs.

Present addresses: ${ }^{5}$ Institute of Biomedicine of the University of Barcelona (IBUB), Baldiri Reixac 15, 08028 Barcelona, Spain; ${ }^{6}$ Control of Stem Cell Potency Group, Institute for Bioengineering of Catalonia (IBEC), Baldiri Reixac 15, 08028 Barcelona, Spain.

${ }^{7}$ Corresponding author.

E-MAIL belmonte@salk.edu and izpisua@cmrb.eu; FAX (858) 453-2573. Article is online at http://www.genesdev.org/cgi/doi/10.1101/gad.1876710.
hESCs were first derived from the pluripotent cells of the blastocyst inner cell mass and can be maintained in vitro indefinitely with the addition of fibroblastic growth factor 2 (FGF2) and other unknown factors secreted from feeder cell layers (Thomson et al. 1998). The pluripotency of hESCs is regulated by a set of unique transcription factors including Oct4, Sox2, and Nanog (Chambers and Smith 2004). It has been shown that a combination of three or four factors of Oct4, Sox2, and KLf4, with or without $\mathrm{Myc}$, can reprogram somatic cells to generate iPSCs (Takahashi and Yamanaka 2006; Takahashi et al. 2007). Analysis of partially reprogrammed iPSCs reveals temporal and separable contributions of the four factors and indicates that ectopic c-Myc acts earlier than the pluripotency regulators (Sridharan et al. 2009). Indeed, overexpression of Myc is known to regulate cyclin $\mathrm{D}_{1}$, promoting cell cycle progression, although it remains unknown if the cell cycle function of c-Myc plays a separate role to the pluripotency genes (Oct4/sox $2 / \mathrm{Klf} 4)$ in 
the reprogramming process (Daksis et al. 1994). Recently, it has been shown that loss of p53 function can enhance the efficiency of reprogramming, suggesting that the cell cycle is a rate-limiting step in the reprogramming process (Zhao et al. 2008; Hong et al. 2009; Kawamura et al. 2009; Li et al. 2009; Utikal et al. 2009). Regulators of p53 transcriptional activity in hESC survival or the reprogramming process remain to be defined.

The cell cycle of mouse ESCs and, to a lesser extent, hESCs has been well described; however, defined functional data are lacking (Savatier et al. 2002; Stead et al. 2002; White and Dalton 2005). The core cell cycle regulatory machinery of ESCs-namely, Cyclins A, E, D, and $\mathrm{B}$, and their kinases CDK2, CDK4, and CDK6-are not regulated in a cyclic fashion, with the exception of cyclin $\mathrm{B}$ (Savatier et al. 2002; Stead et al. 2002). Cyclin $D_{1}$ is a unique cyclin in having a destruction box that responds to cellular stress leading to its degradation and cell cycle arrest (Agami and Bernards 2000). Of the core machinery, cyclins $\mathrm{A} / \mathrm{E} / \mathrm{CDK} 2$ are regarded as constitutively on in mouse ESCs, driving an almost nonexistent G1 phase into $S$ phase in which $60 \%-70 \%$ of ESCs are present. Consequently, the rate of ESC proliferation is much faster, with an average cycle lasting just $12 \mathrm{~h}$ compared with somatic cells (White and Dalton 2005; Becker et al. 2006). A recent study functionally demonstrated that Cyclin A regulates pluripotency, albeit in mouse ESCs, but is redundant in fibroblasts (Kalaszczynska et al. 2009). In addition to these differences, many of the peripheral genes that control cell cycle, such as p16 ${ }^{\mathrm{INK} 4 \mathrm{a}}$, are thought to be inactive, resulting in a different regulation of cell cycle in mouse ESCs (Faast et al. 2004). Given such differences between somatic and pluripotent cells, little is known about the role of the cell cycle in maintaining hESCs or iPSCs in culture. Much less is known about control of apoptosis in hESCs or iPSCs. Recently, the use of a Rho kinase inhibitor has been shown to protect hESCs from apoptosis, and is now used with in vitro culture of hESCs (Watanabe et al. 2007).

We sought to understand the role of the cell cycle and apoptosis in hESCs and formation of iPSCs by investigating the Rem2 GTPase. Rem2 is a recently identified member of the Rem/Rad/Gem/Kir (RGK) family of Rasrelated GTPases, which were first described as overexpressed in muscle cells of patients with type II diabetes mediating signal transduction (Reynet and Kahn 1993; Maguire et al. 1994). Recently, Rem2 was identified from a functional genetic screen to bypass a p53-induced senescence to immortalize somatic cells, demonstrating a fundamental role for cell cycle control (Bierings et al. 2008). Here we hypothesize that the immortalization of cells is a feature very similar to self-renewal of hESCs, suggesting a role for Rem2 in self-renewal.

\section{Results}

Rem2 GTPase is expressed in hESCs, and is essential for self-renewal and pluripotency

We found that Rem2 GTPase is highly expressed in six independent hESC lines derived, compared with human fibroblasts. Protein expression was found to be located predominantly in the cell membrane; however, when Rem2 was forced, overexpressed protein expression was observed in the cytoplasm and nucleus as well (Fig. 1A). We next tested the expression levels during hESC differentiation and found that Rem 2 is down-regulated under general differentiation conditions (Fig. 1B). This suggests that high levels of Rem2 expression are important for maintaining a self-renewing undifferentiated state in hESCs. Given this, we knocked down Rem 2 in hESCs using stably expressed shRNAs and found that loss of Rem 2 caused loss of hESC self-renewal, as evidenced in colony-formation assays (CFAs) (Fig. 1C). With gain of Rem2 function in hESCs, the differences compared with controls suggested an overgrowth of colony formation, which was overgrown deliberately to show the effect of the Rem2 RNAi (Fig. 1C). Shorter-term CFAs also suggested an increase in growth with Rem 2 overexpression (data not shown). To rule out any effects of the virus titer or effect of the virus on the adherence of hESCs to the culture plates following infection, we tested the virus titer and took time-lapse photos following plating and did not observe any significant effect (Supplemental Figs. 1, 2). The karyotype of hESC lines following infection and passaging was found to be normal (Supplemental Fig. 3).

The main molecular markers of pluripotency-such as Oct4, Sox2, Nanog, and Klf4-in hESCs did not appear to be affected by Rem 2 knockdown or overexpression, including c-Myc, even though the hESCs were dying (Fig. 1D). However, molecular markers of differentiation were affected in undifferentiating in vitro conditions (Fig. 1D). To investigate the role of Rem 2 in pluripotency further, we overexpressed Rem 2 in hESCs and differentiated them under general conditions $(20 \%$ fetal calf serum [FCS] on gelatin-coated flasks). We were unable to do the same with loss of function of Rem2 due to the rapid loss of hESC survival (Fig. 1E). Forced expression of Rem2 under general differentiating conditions in vitro pushed ESC fate toward an ectodermal lineage at the expense of mesoderm (Fig. 1E), demonstrating that Rem2 plays a critical role in maintaining a true pluripotent state.

In order to further describe the importance of Rem 2 in hESC biology, we tested a panel of established chemical inhibitors known to affect signaling pathways essential for maintenance of hESCs in vitro. We found that chemical inhibition of FGF receptors caused down-regulation of Rem2, and inhibition of the Rho pathway caused upregulation of Rem2 (Fig. 2A). However, inhibition of the c-Jun N-terminal kinase (JNK) or transforming growth factor (TGF) pathways had no effect on Rem2 expression, suggesting a specific pathway of Rem2 regulation via FGF or Rho pathways (Fig. 2A). To define the role of Rem2 in these pathways further, we overexpressed Rem 2 in hESCs and were able to rescue the FGFr inhibitor effects of slowing hESC growth as assessed by CFA (Fig. 2B). We used a dox-regulated lentiviral vector (a kind gift of Professor L. Naldini); the addition of DOX to cell culture reduced expression of Rem2 in $2 \mathrm{~d}$ (data not shown). To determine if FGF2 regulated Rem2 further, we added FGF2 to the culture medium of human fibroblasts that 
A

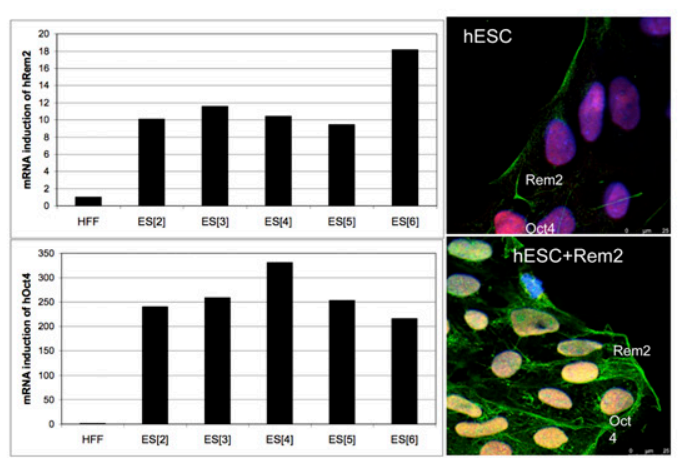

B
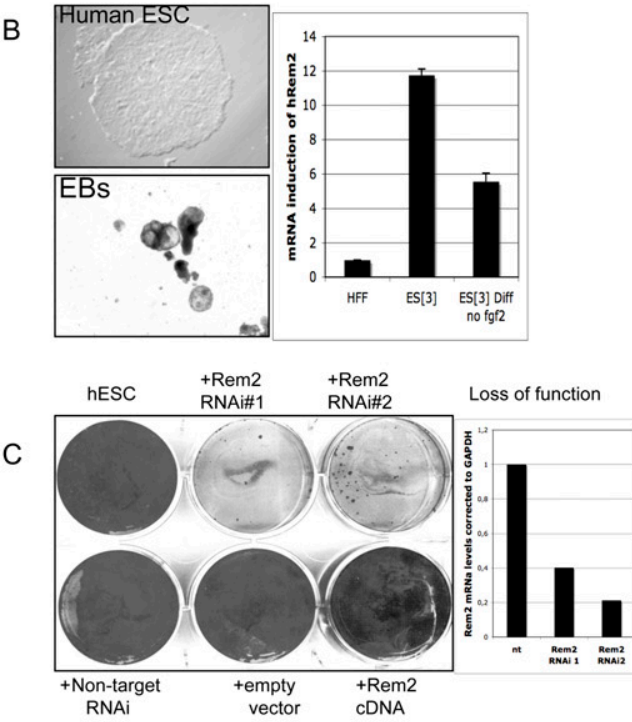

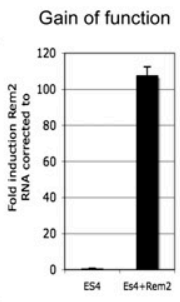

D

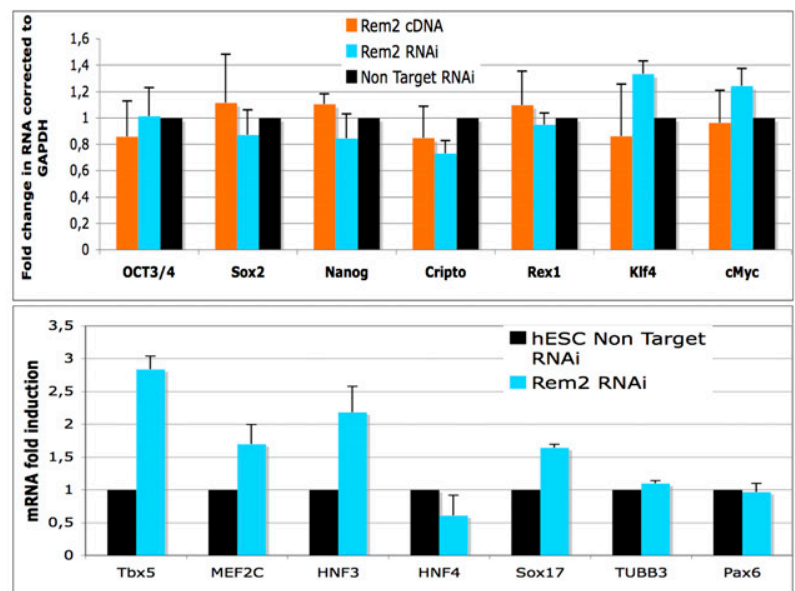

$\mathrm{E}$

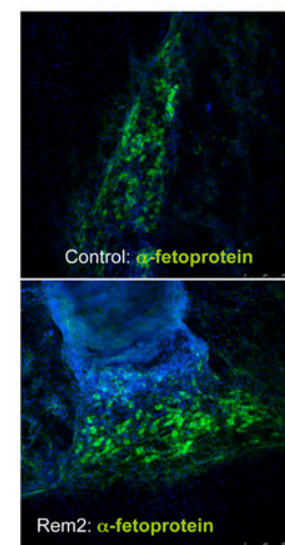

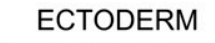

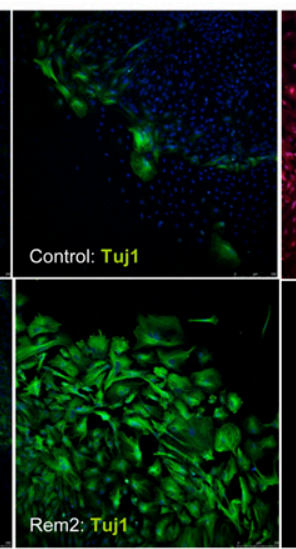

MESODERM

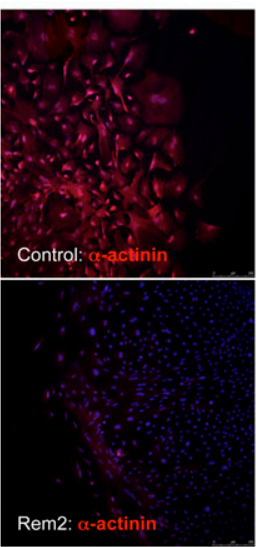

Figure 1. Rem2 GTPase is expressed in hESCs and is essential for self-renewal. (A, left panels) Real-time PCR of Rem2 and Oct4 RNA levels in hESC lines and endogenous Rem2 or ectopic Rem2 localization by immunostaining. (B, left panels) Photographs of differentiation of hESCs into EBs using general conditions on gelatin $(\times 100)$. (Right panel) Real-time PCR levels of Rem2 mRNA. (C, left panel) CFA with gain (cDNA) and loss (RNAi) of function of Rem2 in hESCs in undifferentiating conditions. (Middle right panels) Graphs of real-time PCR levels of Rem2 mRNA levels following treatment with two independent Rem2 RNAi hairpins or nontarget RNAi controls and Rem 2 cDNA in hESCs. ( $D$, top graph) Graph of real-time PCR of mRNA levels of pluripotency genes with gain and loss of function of Rem2. (Bottom graph) Graph of real-time PCR of mRNA levels of differentiation genes with loss of function of Rem2. (E) Photos of immunohistochemical markers of the three germ layers after $20 \mathrm{~d}$ with general in vitro differentiation conditions of hESCs, with or without ectopic Rem2.

express relatively low levels of Rem2 and saw a 10-fold induction of Rem2 RNA with $25 \mathrm{ng} / \mathrm{mL}$ (Fig. 2B). Moreover, we removed FGF2 from hESC culture medium and saw a reduction of Rem2 levels over $5 \mathrm{~d}$ (Fig. $2 \mathrm{~B}$ ), further supporting that FGF2 regulates Rem2 expression. We also chose to investigate the effects of the Rho inhibitor further, as it has been shown previously to control survival of hESCs (Watanabe et al. 2007). Indeed, loss of Rem2 function by RNAi prevented the ability of the Rho inhibitor to promote survival of hESCs, suggesting that Rem2 antagonizes Rho signaling in hESCs to control survival (Fig. 2C). A role of Rem2 family members in antagonizing Rho signaling has been shown before /Olson 2002). Furthermore, the effects of the Rho inhibitor were to increase the cell cycle of hESCs grown on Matrigel rather than protection against apoptosis, which is in contrast to what has been reported previously (Fig. 2C; Watanabe et al. 2007). Together, these data demonstrate that Rem2 is overexpressed in hESCs compared with fibroblasts, controls self-renewal as well as pluripotency of hESCs, and is regulated by and mediates signaling pathways essential for maintaining hESCs in vitro.

Rem2 GTPase cell cycle and apoptosis by regulating cyclin $D_{1}$ expression and localization in hESCs

We next sought to understand the mechanisms by which Rem2 regulates hESC self-renewal using the same gain (cDNA) and loss (RNAi) of gene function strategies described above. We first analyzed the effects of Rem 2 on the cell cycle of hESCs because we showed previously that Rem 2 regulates the cell cycle of endothelial cells via the p53 pathway to immortalize cells (Bierings et al. 2008). Given this, we first examined the effects of Rem2 on p14 ${ }^{\mathrm{ARF}}$ in hESCs, but did not find any effect (Supplemental Fig. 4). This is not surprising, given that many cell 

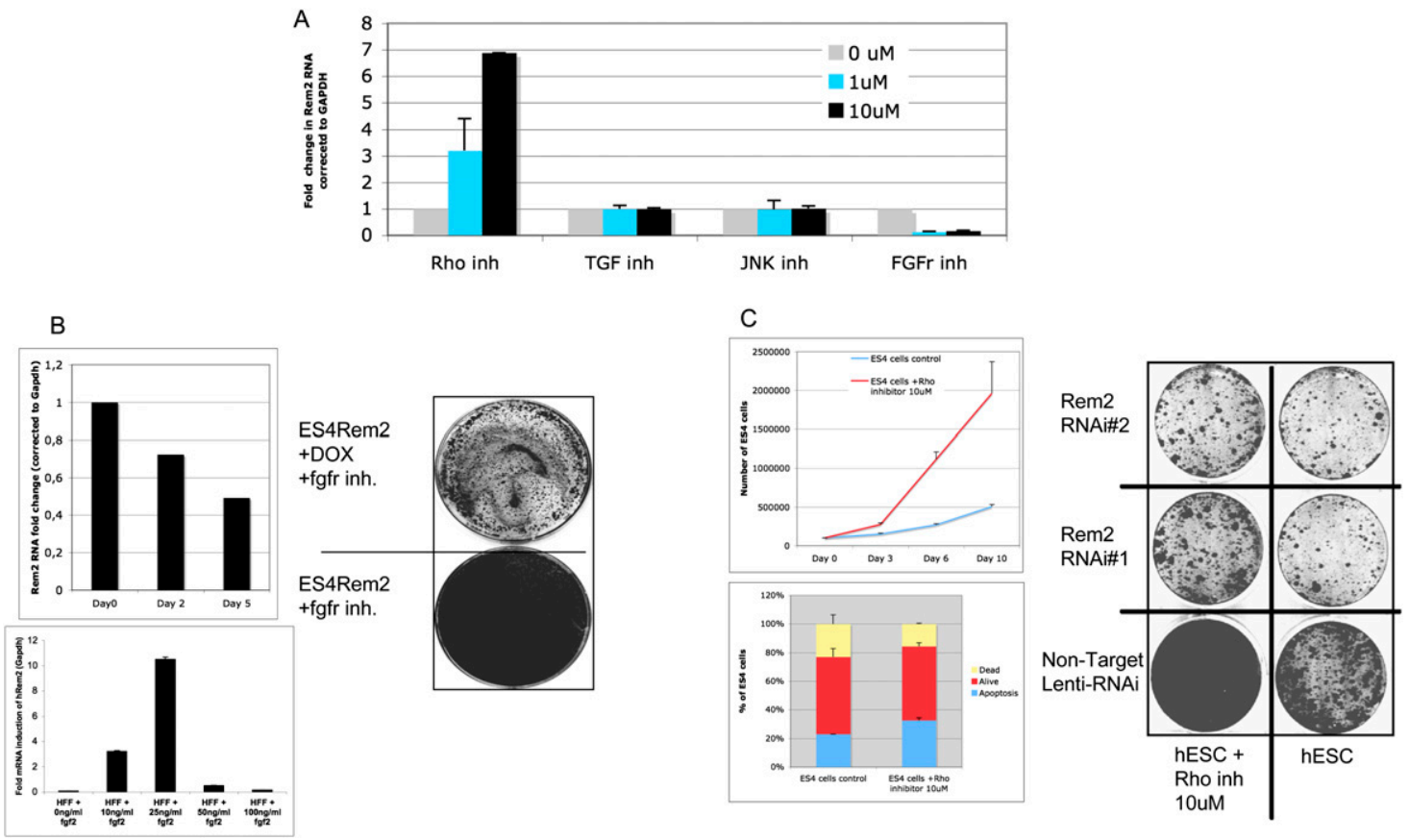

Figure 2. Rem2 is regulated and mediates FGF2/Rho signaling. (A) Graph of real-time PCR of Rem2 RNA levels in hESCs treated with chemical inhibitors of signaling pathways known to be important in hESC survival: FGFr (SU5402), JNK (SP600125), TGF-b-R1 KinaseAlk5 (Inhibitor II), and Rho-kinase (Y-27632). (B, top left panel) Graph showing hESCs cultured without FGF2 in the media and Rem2 expression levels measured by real-time PCR. (Bottom left panel) Real-time PCR of Rem2 expression in human fibroblasts treated with different concentrations of FGF2 growth factor. (Right panel) Rescue of effects of FGFr inhibitor (SU5402) by ectopic Rem2. CFA of Rem2-overexpressing hESC growth on Matrigel with and without DOX plus FGFr inhibitor SU5402. (C, top left panel) Graph of effect of Rho kinase inhibitor on hESC proliferation. (Bottom left panel) Graph representing FACs analysis of apoptosis using DilC in hESCs treated with Rho inhibitor. Note that Rho inhibitor does not protect hESCs from apoptosis, but rather increases proliferation of hESCs cultured on Matrigel. (Right panel) Rescue of Rho inhibitor effects on proliferation by Rem2 RNAi in hESCs by CFA.

cycle pathways such as $\mathrm{p} 16^{\mathrm{INK} 4 \mathrm{a}}$-cyclin $\mathrm{D}$ are not functional in ESCs (Faast et al. 2004). In ESCs, we found that loss of Rem 2 caused a decrease of cells in S phase and an increase in G2/M phase in a short-term experiment (Fig. 3A; Supplemental Figs. 5, 6). With long-term passaging of the cells, we saw that, after 5-7 d, most of the RNAitreated cells were arrested or dead. Conversely, gain of Rem2 function caused an increase in proliferation of hESCs over time, demonstrating that Rem2 is necessary and sufficient for maintaining the rapid cell cycle of hESCs (Fig. 3A). This supports the initial observation using CFA methodology that overexpression of Rem2 increases growth of hESCs (Fig. 1C).

To understand further how loss of Rem2 could be regulating proliferation, we performed a real-time PCR superarray for all cell cycle- and apoptosis-related genes. We found that there were little significant differences of gene expression on the core machinery of cell cycle kinases with loss of Rem2 in hESCs (Fig. 3A). To our surprise, the only exception was up-regulation of cyclin $\mathrm{D}_{1} / \mathrm{CDK} 6$, which normally promotes cell cycle progression-the opposite of what we observed with hESCs treated with Rem2 RNAi (Figs. 1, 3A). We show that the up-regulation of cyclin $\mathrm{D}_{1}$ with loss of Rem2 is partially cytoplasmic in undifferentiated conditions, and suggests that expression of Rem2 expression regulates cyclin $\mathrm{D}_{1}$ localization to maintain cell cycle and survival of hESCs (Fig. 3A). We also observed a deregulation of DNA damage-controlling genes such as BRCA2 by Rem2, which we validated by Western blot analysis, suggesting further a role for protection of apoptosis pathways (Fig. 3A). The apparent specific regulation of DNA damage-controlling genes by Rem2 suggests a more specific regulation than that known for c-Myc.

Given that loss of Rem2 caused hESC death in vitro, we assessed apoptosis using three approaches. With all three approaches-FACs analysis for DilC, DAPI staining, and Western blot for cleaved caspase 3-an increase in apoptosis with loss of Rem2 was observed (Fig. 3B; Supplemental Fig. 7). Overexpression of Rem2 did not reveal a significant change by FACs; however, by Western blot analysis, we observed a decrease in cleaved caspase 3 with Rem2 cDNA in hESCs (Fig. 3B), suggesting that they were protected from apoptosis with overexpression of Rem2 even under nonstress conditions. To test if overexpression of Rem 2 protected hESCs from apoptosis, we treated the hESCs with mitomycin C, an activator of the DNA damage p53/apoptosis pathway. We observed that the hESCs were protected from apoptosis with eightfold more alive cells in Rem2/mitomycin C-treated hESCs compared with controls (Fig. 3C). To dissect the mechanism further, Western blot analyses showed that MDM2 levels, an indirect readout for the transcriptional activity of p53, were not induced in hESC cells with ectopic Rem2 

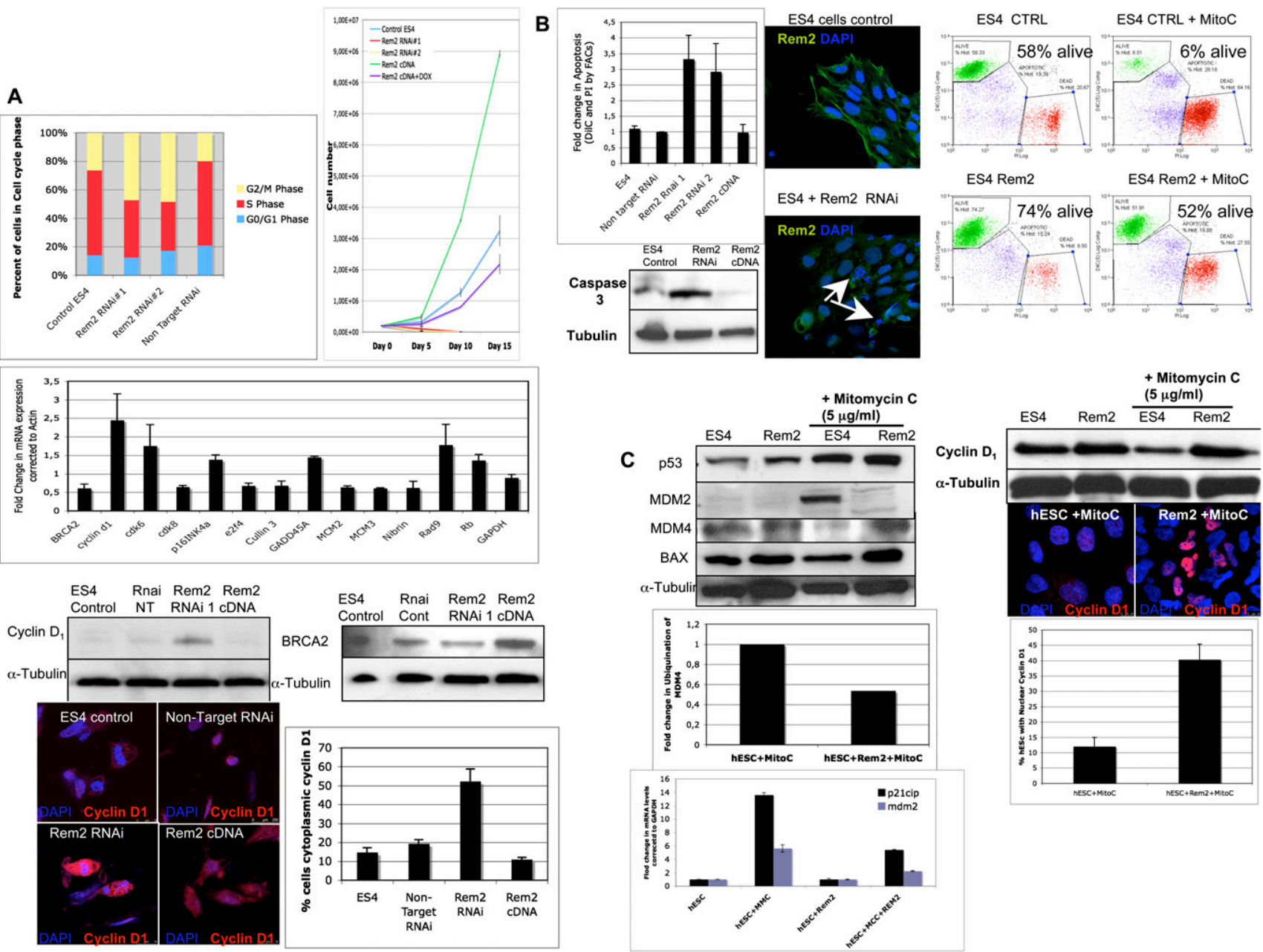

Figure 3. Rem2 GTPase controls cell cycle and apoptosis by regulating cyclin $\mathrm{D}_{1}$ and p53. (A, top left panel) Graph of FACs analysis of cell cycle profile of hESCs with loss of function of Rem2. (Top right panel) Proliferation curve of hESCs with loss and gain of Rem2 function. (Middle left panel) Real-time PCR superarray of cell cycle genes (summary of most significant changes) with loss of Rem2 function compared with nontarget RNAi controls in hESCs. (Bottom left panel) Validation of array using Western blot of cyclin $\mathrm{D}_{1}$ protein levels with loss and gain of Rem 2 function in hESCs. (Bottom right panel) Validation of array by Western blot of BRCA2 protein levels with loss and gain of Rem2 function in hESCs. (Far bottom panel) Photographs of immunostaining with cyclin $\mathrm{D}_{1}$ with loss and gain of Rem2 function in hESCs. The graph shows quantification of the percent of cells expressing high levels of cyclin $\mathrm{D}_{1}$ in the cytoplasm. (B, top left panel) Graph of FACs analysis of apoptosis using DilC and PI staining of hESCs with loss and gain of Rem2 function. (Top middle panels) Photographs of DAPI/Rem2 immunostaining of hESCs with no infection control or with Rem2 RNAi demonstrating apoptotic nuclei with loss of Rem2 function in undifferentiating conditions. (Top right panels) FACs histograms of apoptosis (assessed by DilC) with and without Rem 2 gain of function in hESCs treated with or without $5 \mu \mathrm{g} / \mathrm{mL}$ Mitomycin C. (Bottom left panel) Western blot of activated caspase 3 levels with loss and gain of Rem 2 function in hESCs. (C, top left panel) Western blot analysis of p53 pathway with and without Rem2 gain of function in hESCs treated with or without $5 \mu \mathrm{g} / \mathrm{mL} \mathrm{Mitomycin} \mathrm{C.} \mathrm{(Top} \mathrm{right}$ panel) Western blot of cyclin $\mathrm{D}_{1}$ protein localization and level of expression with and without Rem2 gain of function in hESCs treated with or without $5 \mu \mathrm{g} / \mathrm{mL}$ Mitomycin C. The graph indicates quantification of the percent of hESCs with cyclin $\mathrm{D}_{1}$ protein localization. (Middle left panel) Quantification of ubiquitination assay for MDM4 with or without Rem2 and with or without Mitomycin C treatment demonstrates reduced ubiquitination of MDM4 with Rem2 overexpression in hESCs treated with Mitomycin C compared with input controls (MDM4). Note: A photo of the blot can be seen in Supplemental Figure 8. (Bottom left panel) Graph of real-time PCR of p53 transcriptional targets $M D M 2$ and $p 21^{C I P}$ mRNA levels treated with $5 \mu \mathrm{g} / \mathrm{mL}$ Mitomycin C and with or without Rem2 in hESCs, clearly showing that Rem 2 regulates the transcriptional activity of p53 under stressful conditions.

following mitomycin $\mathrm{C}$ treatment as compared with the clear p53 transcriptional activation observed in the control, suggesting a role for Rem2 in suppressing p53 activation (Fig. 3C). Moreover, MDM4 protein, which is known to bind directly to p53 to inhibit its activity and needs to be degraded in response to stress to allow for p53 activation, was not degraded with mitomycin $\mathrm{C}$ treatment in Rem 2 hESCs, further supporting a role for Rem2 in suppression of the p53 pathway (Fig. 3C). We show that Rem2 prevents the ubiquitination and degradation of MDM4 upon stress, suggesting that Rem2 is a novel and active component in the DNA damage-ubiquitination 
signaling pathway in response to stress (Fig. 3C). To further establish and define that Rem2 suppresses p53 transcriptional activity, we demonstrate that ectopic Rem 2 blocks the induction of MDM 2 and $\mathrm{p} 21^{\mathrm{CIP}}$ mRNA, two transcriptional targets of p53 observed in control cells in the presence of stress, and that a p53 luciferase reporter construct is suppressed following treatment with mitomycin C with ectopic Rem2 (Fig. 3C; Supplemental Fig. 8). Although the fold activation of the p53 luciferase reporter construct by mitomycin $\mathrm{C}$ in controls is small, the obvious suppression by Rem 2 in the presence of mitomycin $\mathrm{C}$ below basal levels $(<1)$ demonstrates clearly the ability of Rem2 to suppress p53 transcriptional activity under stress (Supplemental Fig. 8).

We observed that the FGF2 inhibitor (SU5402) inhibits Rem2 expression and consequently increases Cyclin $D_{1}$ mRNA expression levels, consistent with the Rem2 RNAi data (Fig. 3A), implicating the FGF2 pathway in regulation of Cyclin $\mathrm{D}_{1}$ in hESCs (Supplemental Fig. 9). Moreover, Cyclin $\mathrm{D}_{1}$ has been shown previously to be a target of the DNA damage pathway (Agami and Bernards 2000). Given this, we also examined if Rem 2 controlled cyclin $\mathrm{D}_{1}$ protein level when hESCs were placed under stress with mitomycin treatment. Whereas cyclin $\mathrm{D}_{1}$ normally is degraded in response to cell stress, which we observed in hESCs by Western blot methodology, we show that ectopic Rem 2 protected the degradation of cyclin $\mathrm{D}_{1}$ under stress conditions in hESCs (Fig. 3C). Moreover we observed that stress of Rem2-overexpressing hESCs causes a nuclear localization of cyclin $\mathrm{D}_{1}$, which would enable faster proliferation and survival (Fig. 3C). Therefore, under normal culturing conditions of hESCs, Rem2 maintains cyclin $\mathrm{D}_{1}$ expression and localization, whereas under stressful conditions such as DNA damage, Rem2 maintains cyclin $\mathrm{D}_{1}$ nuclear to promote hESC survival. Taken together, these data define Rem2 as a critical mediator of proliferation and apoptosis in hESCs by suppressing the ability of p53 to transcriptionally induce its targets, as well as the expression/location of cyclin $\mathrm{D}_{1}$ to promote survival and therefore self-renewal of hESCs in vitro.

\section{Rem2 GTPase controls efficiency of reprogramming into iPSCs}

Recent work has demonstrated that ectopic Rem 2 regulates the p53 pathway to immortalize primary cultured cells, indicating a possible role with instating selfrenewal-like properties in somatic cells (Bierings et al. 2008). Moreover, it has been shown that loss of p53 can enhance reprogramming, although regulators of p53 remain to be defined (Zhao et al. 2008; Hong et al. 2009; Kawamura et al. 2009; Li et al. 2009; Utikal et al. 2009). Given that we showed that Rem 2 maintains self-renewal and pluripotency in hESCs, we next asked if Rem 2 could enhance reprogramming of somatic cells into iPSCs. To answer these questions, we reprogrammed somatic cells with three factors alone (Oct4/sox2/Klf4) or with either Myc, cyclin $\mathrm{D}_{1}$, or Rem2 (Supplemental Fig. 10).

We first observed that endogenous Rem2 levels increase in reprogrammed iPSCs, similar to levels of Rem2 in hESCs (Fig. 4A). We also found that cyclin $\mathrm{D}_{1}$ protein levels were highly expressed in iPSCs compared with ESCs (Supplemental Fig. 11). Consequently, we investigated if Rem 2 could increase the number of pluripotent cells reprogramming with just three factors by staining for the early pluripotency marker SSEA4 (Fig. 4B). The increase in proliferation that we observed was correlated to an eightfold increase in SSEA4-positive cells expressing three factors plus Rem2, which was more than that observed from three factors plus c-Myc (Fig. 4B; Supplemental Fig. 12). Next, we asked if Rem2 expression is essential for the reprogramming process by stably knocking down Rem2 using a lentiviral system to deliver shRNAi in human keratinocytes infected with four factors-Oct4, Sox2, Klf4, and c-Myc. We achieved a $50 \%$ knockdown of Rem2 mRNA in human keratinocytes (data not shown), and observed a $60 \%$ loss of alkaline phosphatase (AP)-positive-stained colonies (Fig. 4C). This demonstrates that Rem 2 expression is an essential component of the reprogramming phenomena of somatic cells to iPSCs. The trend of an increase in SSEA4-positive cells with three factors plus Rem2 correlates to the AP staining, thus validating AP staining as a reliable tool for assessment of reprogramming efficiency. We observed no effect of Rem 2 on p14 ${ }^{\mathrm{ARF}}$ levels in keratinocytes or mouse embryonic fibroblasts (MEFs), ruling out regulation of this pathway during iPSC formation (Supplemental Fig. 4). Finally, we overexpressed Rem 2 with just three factors-Oct4, Sox2, and Klf4-to determine if gain of Rem2 function could enhance reprogramming and replace c-Myc. We saw an eightfold increase in efficiency of reprogramming with three factors plus Rem2, which was as efficient as using four factors (Fig. 4C,D).

To check that we had made iPSCs, we overexpressed Rem2 with three or four factors and picked colonies for characterization. Rem 2 iPSC colonies have been named RiPs (Rem2-induced pluripotent stem cells) and were picked between days 12 and 18 for expansion. We observed that RiPs were threefold more likely to survive picking and expansion than other iPSCs, and that four factor plus Rem 2 colonies were more prone to differentiation during expansion than three factors plus Rem2 (data not shown). Further characterization of the RiPs revealed protein expression of ESC markers OCT4, Sox2, Nanog, Tra1-81, Tra1-60, SSEA3, and SSEA4 (Fig. 5A, panels a-1). To determine if RiPs were able to differentiate into the three germ layers, a hallmark of true ESC function, embryoid bodies (EBs) were made using general differentiation conditions, and we show that they were rapidly able to form all three germ cell layers, demonstrating that real iPSCs were made (Fig. 5B, panels $\mathrm{m}-\mathrm{u}$ ). Real-time PCR analysis of the endogenous and transgene expression of the four factors demonstrates that endogenous factors are up-regulated in RiPs and the transgenes are almost all totally silenced (Fig. 5C). We found consistently that the Oct4 transgene shows some residual expression in other studies where we made fully characterized human iPSCs (Aasen et al. 2008). These data demonstrate that Rem2 is able to reprogram human somatic cells into iPSCs with 

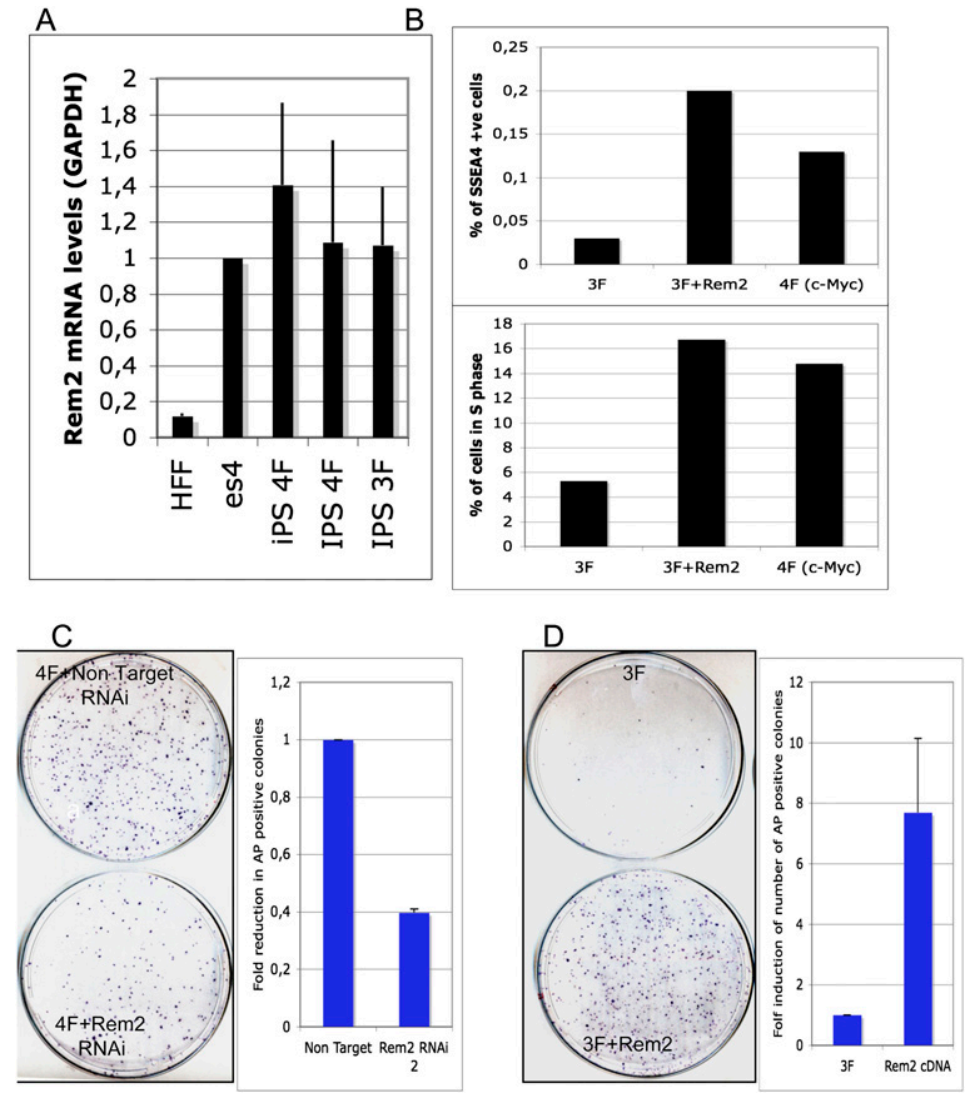

Figure 4. Rem2 GTPase controls efficiency of reprogramming into iPSCs. (A) Graph of real-time PCR of Rem2 levels in fibroblasts compared with iPSCs and hESCs. (B, top panel) Graph of SSEA4 staining of early reprogramming cells (day 12) as analyzed by FACs. The trend of an increase in SSEA4-positive cells with 3F plus Rem2 correlates to the AP staining, thus validating AP staining as a reliable tool for assessment of reprogramming efficiency. (Bottom panel) Graph of FACs analysis of the same cells analyzed for SSEA4 and GFP (a polycistronic Oct4/Sox2/Klf4/Myc or Rem2 GFP-tagged expression vector was used for these reprogramming experiments) for percent of early reprogramming cells in S phase (measured by EDU and DAPI). (C, left panel) Photo of colony formation assay of reprogramming with four factors with Rem2 RNAi or nontarget RNAi stained with AP. (Right panel) Graph of quantification of number of AP-positive colonies with four factors with Rem2 RNAi or nontarget RNAi. (D, left panel) Photo of CFA of reprogramming with three (no c-Myc) factors with Rem2 cDNA or controls stained with AP. (Right panel) Graph of quantification of number of AP-positive colonies with three factors with Rem 2 cDNA or controls stained with AP. just three factors and is as efficient as c-Myc in reprogramming.

\section{Rem2 is dependent on p53 and regulates cyclin $D_{1}$ localization to enhance reprogramming}

We gleaned from the work in hESCs that Rem 2 regulates cyclin $\mathrm{D}_{1}$ expression and localization. Cyclin $\mathrm{D}_{1}$ is a main regulator of the cell cycle and is a target of c-Myc, suggesting further that a change in the cell cycle is required to attain pluripotency during reprogramming. We sought then to understand if the regulation/localization of cyclin $\mathrm{D}_{1}$ is responsible for reprogramming human somatic cells toward iPSCs. We overexpressed wild-type cyclin $\mathrm{D}_{1}$ and a cytoplasmic-expressed cyclin $\mathrm{D}_{1}$ mutant in an attempt to mimic the effects of Rem2 on cyclin $\mathrm{D}_{1}$ regulation and localization in hESCs (Fig. 4A,B). We overexpressed these cyclin $\mathrm{D}_{1}$ constructs with only three factors-Oct4/sox2/Klf4-as Myc is known to regulate cyclin $\mathrm{D}_{1}$ (Daksis et al. 1994). We found that overexpression of wild-type cyclin $\mathrm{D}_{1}$ (a target of c-Myc) increased the efficiency of reprogramming more than threefold, by increasing the number of cells in $S$ phase of the cell cycle $(P=0.009)$, demonstrating that cyclin $\mathrm{D}_{1}$ up-regulation is sufficient for enhancing reprogramming (Fig. 4C,D). However, the converse was true with overexpression of the cytoplasmic cyclin $\mathrm{D}_{1}$ mutant, which caused apoptosis, loss of S-phase cycling cells $(P=0.05)$, and loss of reprogramming capacity (Fig. 4C,D). We observed in hESCs that overexpression of Rem2 under stress conditions in vitro protected hESCs to increase survival by maintaining high levels of cyclin $\mathrm{D}_{1}$ protein (Fig. 2). Because reprogramming is thought to evoke high levels of cellular stress, we measured Cyclin $\mathrm{D}_{1}$ protein levels and location by immunostaining in early reprogramming colonies (at $12 \mathrm{~d}$ ) that were made with three factors alone (Oct4/Sox2/Klf4) with either Rem 2 or c-Myc as well. We show that cyclin $\mathrm{D}_{1}$ is mainly cytoplasmic, where it is inactive, when reprogramming with three factors, which may explain why it is so inefficient compared with four factors. However, there is a clear up-regulation of cyclin $\mathrm{D}_{1}$ protein levels and a shift to the nucleus with three factors plus Rem2, where it is active to phosphorylate Retinoblastoma Protein $(\mathrm{pRb})$ and promote cell cycle progression (Fig. 4E). This was also the case for three factors plus c-Myc, where most early reprogramming cells have nuclear-located cyclin $\mathrm{D}_{1}$ expression (Fig. 4E). Next, we asked whether localization of cyclin $\mathrm{D}_{1}$ was independent of $\mathrm{p} 53$, and found that, in early developing human iPSCs (RNAi for p53) or mouse iPSCs (using p53-null MEFs), loss of p53 did not affect the localization of cyclin $\mathrm{D}_{1}$ by Rem 2 or c-Myc, suggesting that it is independent of p53 (Fig. 4E). Taken together, the data demonstrate that the Rem 2 control of the localization of cyclin $\mathrm{D}_{1}$ is critical to the reprogramming phenomena.

We next asked if the role of Rem2 was independent of the p53 pathway during reprogramming, and if their effects during reprogramming are via proliferation and/or apoptosis pathways. We infected human keratinocytes 
Edel et al.

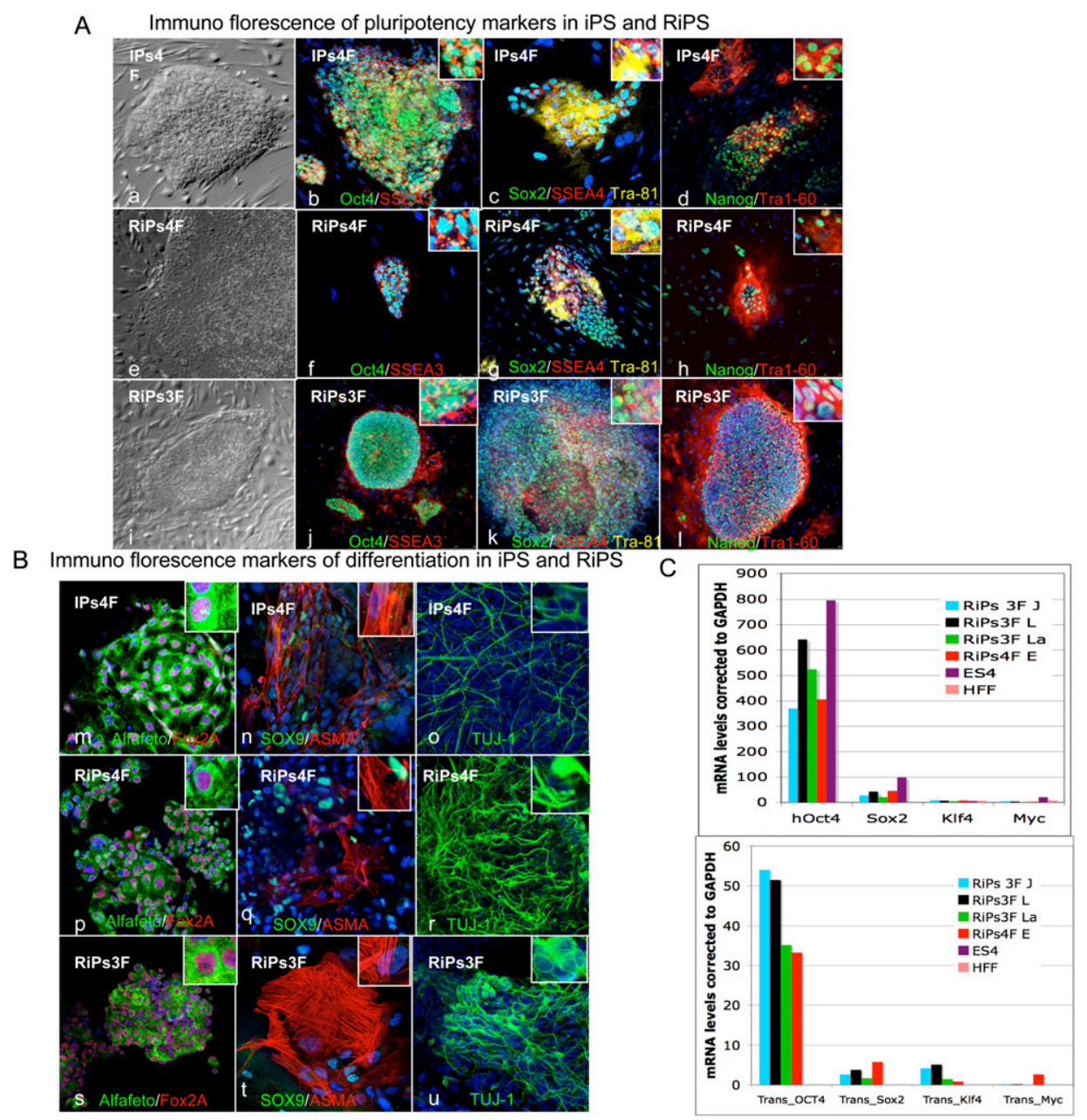

Figure 5. Characterization of RiPs. (A, panels $a-l)$ Phase contrast and immunostaining of iPSCs (one clone) and RiPs (two clones) for pluripotency markers Oct4, SSEA3, Sox2, SSEA4, Tra-81, Nanog, and Tra-60. (B, panels $m-u)$ Immunostaining of differentiation markers following 3 wk of general differentiation of iPSC and RiP clones (gelatin with $20 \%$ FCS medium) for Alfafeto protein, Fox $2 \mathrm{~A}$, Sox9, Alfa smooth muscle (ASMA), and TUJ1. (C) Real-time PCR of transgenes and pluripotency marker expression in RiPs compared with hESCs and somatic cells.

with Rem2, with and without a p53 dominant-negative construct (p53dd), a p53 RNAi construct we published previously (Kawamura et al. 2009), and expression was checked by Western blot analysis (Supplemental Fig. 12). Infected cells were split into CFAs to assess efficiency (on feeder layers) or into slide flasks for assessment of apoptosis (tunnel) and proliferation (phospho-H3) of early reprogramming colonies (day 12) by selecting only SSEA3-positive colonies (Supplemental Fig. 11). We found that loss of p53 with three factors increased efficiency of reprogramming eightfold compared with three factors alone, and this was due to reducing apoptosis and increasing the number of proliferating cells, suggesting that both the apoptotic and cell cycle functions of p53 are critical for the reprogramming process (Fig. 4F,G). In the absence of an active p53, overexpression of Rem2 enhanced reprogramming to $\sim 10$-fold; similar to three factors with p53dd alone, demonstrating that Rem 2 cannot enhance reprogramming in the absence of an active p53 (Fig. 4F,G). Overexpression of Rem 2 or cyclin $\mathrm{D}_{1}$ caused a large increase in the number of SSEA3-positive proliferating cells in early reprogramming colonies, demonstrating that control of cell cycle during reprogramming is essential for the process (Fig. $4 \mathrm{H}$ ). Taken together, these data demonstrate that a cell cycle element is essential for the early reprogramming process, and that Rem2 increases efficiency of early reprogramming events by accelerating proliferation and protection of cells via its regulation of cyclin $\mathrm{D}_{1}$ localization and suppression of $\mathrm{p} 53$ (Fig. 4).

\section{Discussion}

In order to develop further our understanding of human pluripotent ESCs, we investigated the role of Rem2 GTPase because it is known to regulate p53 to immortalize somatic cells, a feature similar to self-renewal of both hESCs and hiPSCs. This study identified Rem2 GTPase as a gene highly expressed in hESCs and iPSCs compared with fibroblasts to promote survival and therefore 
self-renewal of hESCs in vitro. Furthermore, we make the novel discovery that Rem 2 regulates the ability of hESCs to differentiate into all three germ layers, suggesting a role in pluripotency. By manipulating the expressed levels of Rem2, we can force hESCs toward an ectodermal lineage under general differentiating conditions. Rem 2 has been identified in neuronal developments such as control neuron synapse formation (Paradis et al. 2007) and has enriched expression in the central extended amygdala (Becker et al. 2008). Recently, two microarray-based experiments identified Rem 2 as overexpressed in the formation of two different adult stem cells: those making pancreas, and those making dopamine neurons (Lee et al. 2006; Treff et al. 2006). Further work to define the role of Rem2 and its cell cycle targets toward a specific cell fate is warranted.

The control of apoptosis and cell cycle are two essential functions for ESCs to maintain their self-renewal capacity. In hESCs we show that Rem2 regulates cyclin $\mathrm{D}_{1}$ expression and $\mathrm{p} 53$ transcriptional activation controlling cell cycle and apoptosis of hESCs. The regulation of DNA damage genes such as p53 and the cell cycle kinase cyclin $\mathrm{D}_{1}$ suggests that Rem2 is an important regulator of apoptosis and maintaining an ESC-like cell cycle profile. The ability of Rem2 to regulate the localization of cyclin $\mathrm{D}_{1}$ and to suppress p53 transcriptional activity during stress underscores a pivotal functional role for Rem2 to maintain survival and a rapid rate of cell cycle, and therefore self-renewal of hESCs. Indeed, assessment of SSEA4-, SSEA3-, and TRA1-60-positive cells with three factors (Oct4/Sox2/Klf4) plus Rem2 during reprogramming reveals that Rem2 can increase the number of pluripotent cells during the early reprogramming process (Fig. 6H). By using either p53RNAi or p53dd cells for reprogramming, and FACs sorting for SSEA3- or TRA160-positive cells, Rem2 cannot enhance reprogramming. This suggests that Rem2's main mechanism of action is via the p53 pathway (Fig. 6F,H). We also showed that overexpression of cyclin $\mathrm{D}_{1}$, which is also a target of c-Myc, increases the number of SSEA4-positive cells in $S$ phase (Fig. 4B), demonstrating for the first time that the cell cycle functions of c-Myc plays an important role in the efficiency of reprogramming. Taken together, the data clearly define that the core machinery of the cell cyclenamely, cyclin $\mathrm{D}_{1}$-is a rate-determining step in the reprogramming phenomena. We propose that imposing a hESC-like cell cycle profile in somatic cells with Rem2 or cyclin $\mathrm{D}_{1}$, in addition to the pluripotency module (Oct4/Sox2/Klf4), may be a safer and more efficient way to make iPSCs. It remains to be defined if other cell cycle genes overlap with pluripotency or not, which future gain- and loss-of-function studies of other cell cycle genes would reveal.

When we stressed hESCs with a DNA-damaging agent, we observed that cyclin $\mathrm{D}_{1}$ is degraded, as expected. With overexpression of Rem2 in the presence of stress, cyclin $\mathrm{D}_{1}$ is not degraded in hESCs and moves nuclear, relative to hESCs without Rem2 but equally stressed, suggesting that localization of cyclin $\mathrm{D}_{1}$ is critical for maintaining self-renewal and pluripotency. Indeed, overexpression of
Rem2 during the early reprogramming stages up-regulates and maintains cyclin $\mathrm{D}_{1}$ exclusively nuclear, further supporting that cyclin $\mathrm{D}_{1}$ localization is an important rate-determining step during acquisition of pluripotency (Fig. 6E). Moreover, overexpression of a mutant cyclin $\mathrm{D}_{1}$ that is cytoplasmically expressed (to mimic the effects of loss of Rem2 on cyclin $\mathrm{D}_{1}$ in hESCs) caused an increase in apoptosis of somatic cells and loss of reprogramming efficiency, consistent with the idea that maintenance of proper cyclin $\mathrm{D}_{1}$ location in human pluripotent cells is essential for self-renewal and pluripotency. This critical function of Rem2 to regulate Cyclin $\mathrm{D}_{1}$ under stressful conditions (which reprogramming presents to a cell), and to maintain it nuclear during early reprogramming, increases the efficiency of reprogramming by accelerating the cell cycle. The phosphorylation of $\mathrm{Rb}$ has been described as a ground state of the hESC cell cycle profile, suggesting that Rem 2 can instate a hESC cell cycle profile during reprogramming. The novel discovery that the localization and overexpression of cyclin $D_{1}$ controls reprogramming defines a critical role for the cell cycle during the reprogramming process. How Rem 2 controls cyclin $\mathrm{D}_{1}$ localization during reprogramming to achieve pluripotency remains to be defined, although modification of the ubiquitination and protein transport pathways seem likely pathways involved. Rem2 GTPase is a unique GTPase in having an extended $\mathrm{N}$-terminal protein tail with many signal transduction-binding sites, and we did not rule out the GTPase activity of Rem2 in regulating cell survival decisions.

Indeed, the process of reprogramming is thought to evoke huge cellular stresses caused by the introduction of the four factors and the viral or transfection procedures themselves. It follows then that the introduction of genes such as Rem 2 in somatic cells, which can control the effects of cellular stresses, increases survival and therefore the efficiency of reprogramming. Here we show that Rem2 GTPase can enhance the reprogramming efficiency of somatic cells into iPSCs eightfold (Fig. 4). This supports the hypothesis that loss of p53 signaling is an important step in making reprogramming more efficient, and suggests that signaling proteins upstream of p53 are important contributors to reprogramming by monitoring cellular stress levels.

In conclusion, the identification of Rem 2 function in hESCs and reprogramming will help with understanding the molecular mechanisms of survival and proliferation that are essential for self-renewal and pluripotency of hESCs. Our studies highlight the possibility of reprogramming somatic cells by imposing hESC-specific cell cycle features-rather than relying on oncogenes such as c-Myc_-for making safer iPSCs for cell therapy use.

\section{Materials and methods}

\section{Culture of hESCs}

hESCs were derived and fully characterized at the CMR[B] (Raya et al. 2008). They were maintained on either human feeder layers or on Matrigel-coated plates with HUES medium, consisting of 


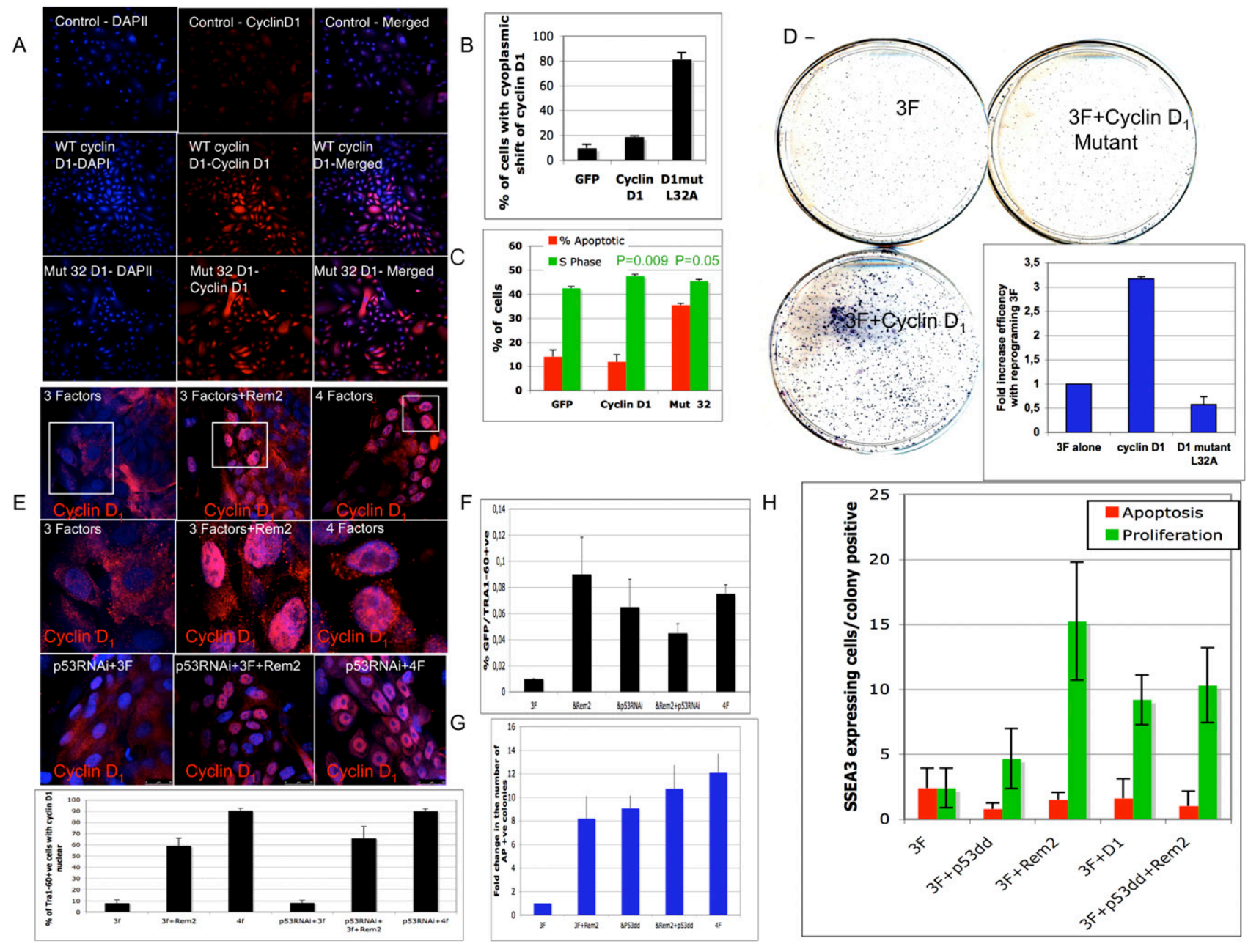

Figure 6. Rem 2 is dependent on $\mathrm{p} 53$ and regulates cyclin $\mathrm{D}_{1}$ localization to enhance reprogramming. (A) Photographs of immunostaining with cyclin $\mathrm{D}_{1}$ in somatic cells before reprogramming, overexpressing GFP (control), cyclin $\mathrm{D}_{1}$, and cyclin $\mathrm{D}_{1}$ mutant (L32A). Magnification, 200×. (B) Graph of the quantification of the number of somatic cells before reprogramming expressing cyclin $\mathrm{D}_{1}$ in the cytoplasm, demonstrating that the expression of the mutant cyclin $\mathrm{D}_{1}$ is more cytoplasmic. $(C)$ Graph summarizing FACs analysis of the percent of cells in S phase or apoptotic cells by DilC plus PI staining for overexpressing GFP (control), cyclin $\mathrm{D}_{1}$, and cyclin $\mathrm{D}_{1}$ mutant (L32A) in somatic cells before reprogramming, demonstrating that the mutant causes apoptosis and reduced proliferation. $P$-values given by a Student's $t$-test. $(D)$ Photo of CFA of reprogramming colonies at day 21 with three factors, three factors plus cyclin $\mathrm{D}_{1}$, or three factors plus cyclin $\mathrm{D}_{1}$ mutant (L32A) stained with AP. (Insert) The number of colonies was quantified by image analysis software and is presented as a graph, demonstrating loss of reprogramming efficiency with expression of mutant cyclin $\mathrm{D}_{1}$. $(E)$ Photos of localization of cyclin $\mathrm{D}_{1}$ during early reprogramming (at day 12), demonstrating a nuclear localization with ectopic Rem2 plus three factors (Oct4/Sox2/Klf4) and three factors plus c-Myc (four factors). P53 RNAi-treated cells were also reprogrammed, and demonstrate nuclear localization of cyclin $\mathrm{D}_{1} .(E)$ Graph of quantification of percent of cells with nuclear-located cyclin $\mathrm{D}_{1} \cdot(F)$ Assessment of Tra1-60-positive cells in early reprogramming colonies with p53 RNAi-treated cells, Rem2 and c-Myc (4F) assessed by FACs analysis. $(G)$ Assessment of AP-positive colonies in early reprogramming colonies with p53dd-treated cells. The number of colonies was quantified by image analysis software and is presented as a graph. $(H)$ Quantification of proliferation and apoptosis in early developing reprogramming colonies with three factors (Oct4/Sox2/Klf4) plus Rem2 or cyclin $\mathrm{D}_{1}$ or p53dd at day 12 by immunostaining for tunnel (red bars), phospho-H3 (green bars), and SSEA3 (to assess specific reprogramming colonies) for different gene treatments as described in the figure.

KO-DMEM (Invitrogen) supplemented with 10\% KO-Serum Replacement (Invitrogen), 0.5\% human albumin (Grifols), $2 \mathrm{mM}$ Glutamax (Invitrogen), $50 \mu \mathrm{M}$ 2-mercaptoethanol (Invitrogen), nonessential amino acids (Cambrex), and $10 \mathrm{ng} / \mathrm{mL}$ bFGF (Peprotech). Cultures were maintained at $37^{\circ} \mathrm{C}, 5 \% \mathrm{CO}_{2}$, with media changes every other day. hESCs were routinely tested for normal karyotype. For hESC lines adapted to Matrigelcoated plates, HUES-conditioned medium from irradiated MEFs was used instead. MEFs were cultured using 10\% FCS with Dulbecco's modified Eagle's medium (DMEM).

\section{Constructs and lentivirus production}

Rem2 cDNA made from RNA extracted from hESCs was cloned into the pCCL TET-off-inducible lenti-vector. Rem2 RNAi constructs and nontarget RNAi controls were purchased from 
RZPD and were cloned into the pLKO.1puro lenti-vector (SigmaAldrich). All lentiviruses were made using a third-generation approach. Briefly, MDL $(6.5 \mu \mathrm{g}), V S V(4 \mu \mathrm{g}), \operatorname{REV}(2.5 \mu \mathrm{g})$, and lentiviral constructs $(10 \mu \mathrm{g})$ were transfected into 293T cells using Lipofectamine2000 overnight. 293T cells (American Type Culture Collection no. CRL-12103) were used for the production of lentiviruses. These cell lines were grown in DMEM (GIBCO) supplemented with $10 \%$ fetal bovine serum (FBS; Biowhitaker). The next day, medium was refreshed, and the following day virus was harvested, tested for titer using an HIV-1 p24 ELISA kit (Perkin Elmer), and stored at $-80^{\circ} \mathrm{C}$ in $1-\mathrm{mL}$ aliquots. hESCs $(200,000)$ were infected in suspension with $1 \mathrm{~mL}$ of viral supernatant for $1 \mathrm{~h}$ at $37^{\circ} \mathrm{C}$ and then plated in six-well Matrigelcoated plates with a further $1 \mathrm{~mL}$ of conditioned media. The next day, media was changed, cells were allowed to recover, and experiments were performed. For proliferation curves, equal cells were plated and then counted every $5 \mathrm{~d}$.

\section{Constructs and retroviral production}

Cyclin $D_{1}$ pBabe puro cDNA constructs were a kind gift from Reuven Agami (Agami and Bernards 2000). cDNAs for Rem2, Oct4, and Sox2 were amplified from ES[4] total RNA by RTPCR. Klf-4 was amplified from IMAGE clone 5111134. c-Myc T58A mutant cDNA was amplified from DNA kindly provided by Dr. Luciano DiCroce. The amplified cDNAs were cloned into the EcoRI/ClaI sites of a modified pMSCVpuro vector, which allows the expression of $\mathrm{N}$-terminal Flag-tagged proteins. The single polycistronic vector containing three factors (Oct4, Sox2, and Klf4) or four factors plus a GFP tag has been described elsewhere (Gonzalez et al. 2009). Retroviruses for the four factors were produced independently after transfecting the cell line Phoenix Amphotropic using Fugene 6 reagent (Roche) according to the manufacturer's directions. After $24 \mathrm{~h}$, the DMEM was replaced, cells were incubated at $32^{\circ} \mathrm{C}$, and the viral supernatant was harvested after $24 \mathrm{~h}$ and $48 \mathrm{~h}$.

\section{Generation of iPSCs}

The generation of iPSCs using human primary keratinocytes has been described before (Aasen et al. 2008). Briefly, cells were isolated from juvenile foreskins (2-16 yr old) using dispase to remove the dermis from the epidermis followed by trypsinization and culture in serum-free low-calcium medium (Epilife; Invitrogen) at $37^{\circ} \mathrm{C}, 5 \% \mathrm{CO}_{2}, 5 \% \mathrm{O}_{2}$, and used between two and four passages. For reprogramming experiments, $\sim 50,000$ or 100,000 cells were seeded per well of a six-well plate and infected with a virus from a polycistronic vector (Oct4, Sox2, and Klf4 plus Rem2) or with a 1:1:1:1 mix of retroviral supernatants of Flag-tagged Rem2, OCT4, SOX2, KLF4, and c-MYCT58A in the presence of $1 \mathrm{mg} / \mathrm{mL}$ polybrene. Infection consisted of a 45-min spinfection at $750 g$, washed with PBS and with keratinocyte medium replaced. Two rounds of infections on consecutive days were performed. Two days after beginning the last round of infection, cells were trypsinized and seeded onto feeder layers of irradiated MEFs in the same culture medium. The medium was changed upon plating to hESC medium, consisting of KODMEM (Invitrogen) supplemented with $10 \%$ KO-Serum Replacement (Invitrogen), 0.5\% human albumin (Grifols), $2 \mathrm{mM}$ Glutamax (Invitrogen), $50 \mu \mathrm{M}$ 2-mercaptoethanol (Invitrogen), nonessential amino acids (Cambrex), and $10 \mathrm{ng} / \mathrm{mL}$ bFGF (Peprotech). Cultures were maintained at $37^{\circ} \mathrm{C}, 5 \% \mathrm{CO}_{2}$, with media changes every other day. IPSCs were picked, expanded, and characterized. For CFA experiments, plates were fixed with $50 \%$ methanol $/ 10 \%$ acetic acid $/ 40 \%$ water for $5 \mathrm{~min}$, stained with $0.1 \%$ Coomassie blue for $5 \mathrm{~min}$, and washed with water, and an electronically scanned photo was produced.

\section{Immunofluorescence and AP analysis}

Cells were grown on plastic coverslide chambers and fixed with $4 \%$ paraformaldehyde (PFA). The antibodies used have been described before (Aasen et al. 2008). Rem 2 antibody has been described before (Bierings et al. 2008). Cyclin $\mathrm{D}_{1}$ was used at 1:100 (Santa Cruz Biotechnologies). The secondary antibodies used were all the Alexa Fluor series from Invitrogen (all 1:500). Images were taken using a Leica SP5 confocal microscope. Direct AP activity was analyzed using an Alkaline Phosphatase Blue/Red Membrane Substrate solution kit according to the manufacturer's guidelines (Sigma).

\section{Chemical inhibitors}

Inhibitors were used at the concentration and time described in Figure 2 or with vehicle alone. FGFr (SU5402), JNK (SP600125), TGF-b-R1 Kinase-Alk5 (Inhibitor II), and Rho-kinase (Y-27632) were all purchased from Calbiochem.

\section{In vitro differentiation}

Differentiation toward endoderm, mesoderm, and neuroectoderm was carried out by plating EBs on gelatin and DMEM medium with $20 \%$ FCS changed every second day for 2-3 wk. Cells were then stained for appropriate markers as described in the figures.

\section{Flow cytometry analyses}

All analyses were performed on a MoFlo cell sorter (DakoCytomation) running Summit software. For measuring apoptosis and proliferation, we used the commercial kits from Invitrogen-the "MitoProbe DilC1(5) Assay kit" and the "Click-iT EdU AlexaFluor647 Flow Cytometry Assay kit," respectivelyfollowing the manufacturer's instructions. For the proliferation assay using the click-IT kit, instead of using the supplied DNA dyes, we used a homemade DNA DAPI-staining solution $10.1 \mathrm{M}$ Tris Base at $\mathrm{pH} 7.4,0.9 \%$ or $150 \mathrm{mM} \mathrm{NaCl}, 1 \mathrm{mM} \mathrm{CaCl}_{2}, 0.5 \mathrm{mM}$ $\mathrm{MgCl}_{2}, 0.2 \%$ BSA, $0.1 \%$ Nonidet NP- $40,10 \mathrm{mg} / \mathrm{mL} \mathrm{DAPI)} \mathrm{at}$ $0.5 \mathrm{~mL}$ per test $\left(2 \mathrm{~h}\right.$ at room temperature or overnight at $\left.4^{\circ} \mathrm{C}\right)$.

\section{Western blot}

Western blot analyses were performed as described previously, using extracts of cells collected by centrifugation, washed twice in PBS, lysed in $1 \times$ lysis buffer $(50 \mathrm{nM}$ Tris- $\mathrm{HCl}, 70 \mathrm{mM}$ 2-mercaptoethanol, $2 \%$ sodium dodecylsulfate [SDS]), then boiled for $5 \mathrm{~min}$ and subjected to $12 \%$ polyacrylamide SDS gel electrophoresis. After electrophoresis, proteins were transferred to a nitrocellulose membrane using a submerged transfer apparatus (Bio-Rad) filled with $25 \mathrm{mM}$ Tris Base, $200 \mathrm{mM}$ glycine, and $20 \%$ methanol. After blocking with $5 \%$ nonfat dried milk in TBS-T (50 mM Tris- $\mathrm{HCl}$ at $\mathrm{pH} 8.0,150 \mathrm{mM} \mathrm{NaCl}, 0.1 \%$ Tween $20)$, the membrane was incubated with the primary antibodies diluted in TBS-T and washed extensively. Primary antibodies were anti-Flag (Sigma), BRCA-1 (Santa Cruz Biotechnologies), p53 (Santa Cruz Biotechnologies, D01), MDM2 (4B2) (Chen et al. 1993), MDM4 (Affinity, bioreagents PA1-24307), Bax (Santa Cruz Biotechnologies), tubulin, and cleaved Caspase 3 (Cell Signaling, 5A1). The membrane was washed three times with TBS-T and then incubated with the appropriate horseradish peroxidaselinked secondary antibody (Amersham). The detection was 
performed with the Western Breeze Immunodetection kit (Invitrogen). The concentration of protein was measured by the Bradford assay. For the ubiquitination assay for MDM4, we used a previously described protocol (Xirodimas et al. 2001). Briefly, hESCs were infected with ubiquitin lentivirus, and stably expressed Ub-hESCs were then infected again with Rem2. Cells were then treated with Mitomycin C, and the ubiquitination assay for MDM4 was performed.

\section{Real-time PCR}

Total mRNA was isolated using Trizol and $1 \mu \mathrm{g}$ was used to synthesize cDNA using the Invitrogen Cloned AMV First-Strand cDNA synthesis kit. One microliter to $2 \mu \mathrm{L}$ of the reaction were used to quantify gene expression by quantitative PCR for transgenes, endogenous pluripotent genes, as described previously (Aasen et al. 2008). For analysis of cell cycle and apoptosisrelated genes, we used a real-time PCR superarray for human cell cycle genes. For Rem2, MDM2, and cyclin $D_{1}$, we used the following primers: hRem2: FOR, AGATGCCACGCTACTAAA GAAG, and REV, GCCCAAGGAGTCAGACGAGCCA; $h$ Cyclin $D_{1}$ : FOR, GATCAAGTGTGACCCGGACT, and REV, TCCTC CTCCTCTTCCTCCTC; hMDM2: FOR, TGTTGGTGCACAA AAAGACA, and REV, CACGCCAAACAAATCTCCTA; $p 21$ : FOR, ACCTGTCACTGTCTTGTACCCTTGT, and REV, GTTT GGAGTGGTAGAAATCTGTCATG.

Real-time PCR superarrays for cell cycle genes were purchased, and the manufacturer's instructions were followed (SA Biosciences).

\section{Quantification using computer-aided analysis software}

Analysis of the number of colonies in CFAs was done using computer-assisted video analysis using Metamorph software. Briefly, a region of interest was set in a photograph of the CFA, a threshold for color was set (blue), and the number of colonies was exported directly to Excel for analysis. All data were analyzed using Excel spreadsheet software for mean, standard deviation, and Student's $t$-test.

\section{Acknowledgments}

We are indebted to José Miguel Andrés Vaquero for assistance with flow cytometry; Meritxell Carrió for expert assistance with cell culture techniques; Esther Melo, Lola Mulero Pérez, and Mercé Gaudes Martí for bioimaging assistance; and Reuven Agami for the cyclin $\mathrm{D}_{1}$ constructs. Cristina Menchon is partly supported by a predoctoral grant from MICINN. This work was supported by grants from the Fondo de Investigaciones Sanitarias, MICINN, RETICS, CIBER, Fundacion Cellex, and The G. Harold and Leila Y. Mathers Charitable Foundation.

\section{References}

Aasen T, Raya A, Barrero MJ, Garreta E, Consiglio A, Gonzalez F, Vassena R, Bilic J, Pekarik V, Tiscornia G, et al. 2008. Efficient and rapid generation of induced pluripotent stem cells from human keratinocytes. Nat Biotechnol 26: 12761284.

Agami R, Bernards R. 2000. Distinct initiation and maintenance mechanisms cooperate to induce G1 cell cycle arrest in response to DNA damage. Cell 102: 55-66.

Becker KA, Ghule PN, Therrien JA, Lian JB, Stein JL, van Wijnen AJ, Stein GS. 2006. Self-renewal of human embryonic stem cells is supported by a shortened G1 cell cycle phase. J Cell Physiol 209: 883-893.
Becker JA, Befort K, Blad C, Filliol D, Ghate A, Dembele D, Thibault C, Koch M, Muller J, Lardenois A, et al. 2008. Transcriptome analysis identifies genes with enriched expression in the mouse central extended amygdala. Neuroscience 156: 950-965.

Bierings R, Beato M, Edel MJ. 2008. An endothelial cell genetic screen identifies the GTPase Rem2 as a suppressor of p19 $19^{\text {ARF }}$ expression that promotes endothelial cell proliferation and angiogenesis. J Biol Chem 283: 4408-4416.

Chambers I, Smith A. 2004. Self-renewal of teratocarcinoma and embryonic stem cells. Oncogene 23: 7150-7160.

Chen J, Marechal V, Levine AJ. 1993. Mapping of the p53 and mdm-2 interaction domains. Mol Cell Biol 13: 4107-4114.

Daksis JI, Lu RY, Facchini LM, Marhin WW, Penn LJ. 1994. Myc induces cyclin D1 expression in the absence of de novo protein synthesis and links mitogen-stimulated signal transduction to the cell cycle. Oncogene 9: 3635-3645.

Faast R, White J, Cartwright P, Crocker L, Sarcevic B, Dalton S. 2004. Cdk6-cyclin D3 activity in murine ES cells is resistant to inhibition by p16(INK4a). Oncogene 23: 491-502.

Gonzalez F, Barragan Monasterio M, Tiscornia G, Montserrat Pulido N, Vassena R, Batlle Morera L, Rodriguez Piza I, Izpisua Belmonte JC. 2009. Generation of mouse-induced pluripotent stem cells by transient expression of a single nonviral polycistronic vector. Proc Natl Acad Sci 106: 89188922.

Hong $\mathrm{H}$, Takahashi $\mathrm{K}$, Ichisaka $\mathrm{T}$, Aoi $\mathrm{T}$, Kanagawa $\mathrm{O}$, Nakagawa M, Okita K, Yamanaka S. 2009. Suppression of induced pluripotent stem cell generation by the p53-p21 pathway. Nature 460: 1132-1135.

Kalaszczynska I, Geng Y, Iino T, Mizuno S, Choi Y, Kondratiuk I, Silver DP, Wolgemuth DJ, Akashi K, Sicinski P. 2009. Cyclin A is redundant in fibroblasts but essential in hematopoietic and embryonic stem cells. Cell 138: 352-365.

Kawamura T, Suzuki J, Wang YV, Menendez S, Morera LB, Raya A, Wahl GM, Belmonte JC. 2009. Linking the p53 tumour suppressor pathway to somatic cell reprogramming. Nature 460: 1140-1144.

Lee MS, Jun DH, Hwang CI, Park SS, Kang JJ, Park HS, Kim J, Kim JH, Seo JS, Park WY. 2006. Selection of neural differentiation-specific genes by comparing profiles of random differentiation. Stem Cells 24: 1946-1955.

Li H, Collado M, Villasante A, Strati K, Ortega S, Canamero M, Blasco MA, Serrano M. 2009. The Ink4/Arf locus is a barrier for iPS cell reprogramming. Nature 460: 1136-1139.

Maguire J, Santoro T, Jensen P, Siebenlist U, Yewdell J, Kelly K. 1994. Gem: An induced, immediate early protein belonging to the Ras family. Science 265: 241-244.

Olson MF. 2002. Gem GTPase: Between a ROCK and a hard place. Curr Biol 12: R496-R498. doi: 10.1016/S09609822(02)00968-5.

Paradis S, Harrar DB, Lin Y, Koon AC, Hauser JL, Griffith EC, Zhu L, Brass LF, Chen C, Greenberg ME. 2007. An RNAi-based approach identifies molecules required for glutamatergic and GABAergic synapse development. Neuron 53: 217-232.

Raya A, Rodriguez-Piza I, Aran B, Consiglio A, Barri PN, Veiga A, Izpisua Belmonte JC. 2008. Generation of cardiomyocytes from new human embryonic stem cell lines derived from poor-quality blastocysts. Cold Spring Harb Symp Quant Biol 73: $127-135$.

Reynet C, Kahn CR. 1993. Rad: A member of the Ras family overexpressed in muscle of type II diabetic humans. Science 262: 1441-1444.

Savatier P, Lapillonne H, Jirmanova L, Vitelli L, Samarut J. 2002. Analysis of the cell cycle in mouse embryonic stem cells. Methods Mol Biol 185: 27-33. 
Sridharan R, Tchieu J, Mason MJ, Yachechko R, Kuoy E, Horvath S, Zhou Q, Plath K. 2009. Role of the murine reprogramming factors in the induction of pluripotency. Cell 136: $364-377$.

Stead E, White J, Faast R, Conn S, Goldstone S, Rathjen J, Dhingra U, Rathjen P, Walker D, Dalton S. 2002. Pluripotent cell division cycles are driven by ectopic $\mathrm{Cdk} 2$, cyclin $\mathrm{A} / \mathrm{E}$ and E2F activities. Oncogene 21: 8320-8333.

Takahashi K, Yamanaka S. 2006. Induction of pluripotent stem cells from mouse embryonic and adult fibroblast cultures by defined factors. Cell 126: 663-676.

Takahashi K, Tanabe K, Ohnuki M, Narita M, Ichisaka T, Tomoda K, Yamanaka S. 2007. Induction of pluripotent stem cells from adult human fibroblasts by defined factors. Cell 131: 861-872.

Thomson JA, Itskovitz-Eldor J, Shapiro SS, Waknitz MA, Swiergiel JJ, Marshall VS, Jones JM. 1998. Embryonic stem cell lines derived from human blastocysts. Science 282: 1145-1147.

Treff NR, Vincent RK, Budde ML, Browning VL, Magliocca JF, Kapur V, Odorico JS. 2006. Differentiation of embryonic stem cells conditionally expressing neurogenin 3. Stem Cells 24: 2529-2537.

Utikal J, Polo JM, Stadtfeld M, Maherali N, Kulalert W, Walsh RM, Khalil A, Rheinwald JG, Hochedlinger K. 2009. Immortalization eliminates a roadblock during cellular reprogramming into iPS cells. Nature 460: 1145-1148.

Watanabe K, Ueno M, Kamiya D, Nishiyama A, Matsumura M, Wataya T, Takahashi JB, Nishikawa S, Nishikawa S, Muguruma $\mathrm{K}$, et al. 2007. A ROCK inhibitor permits survival of dissociated human embryonic stem cells. Nat Biotechnol 25: 681686.

White J, Dalton S. 2005. Cell cycle control of embryonic stem cells. Stem Cell Rev 1: 131-138.

Xirodimas D, Saville MK, Edling C, Lane DP, Lain S. 2001. Different effects of p14 ${ }^{\text {ARF }}$ on the levels of ubiquitinated p53 and Mdm2 in vivo. Oncogene 20: 4972-4983.

Zhao Y, Yin X, Qin H, Zhu F, Liu H, Yang W, Zhang Q, Xiang C, Hou P, Song Z, et al. 2008. Two supporting factors greatly improve the efficiency of human iPSC generation. Cell Stem Cell 3: 475-479. 


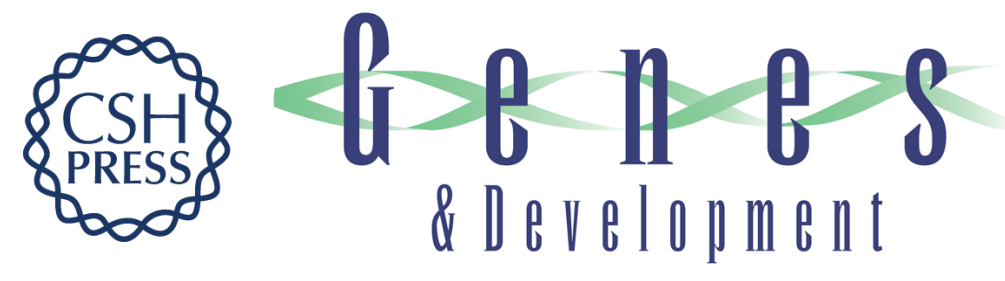

\section{Rem2 GTPase maintains survival of human embryonic stem cells as well as enhancing reprogramming by regulating p53 and cyclin $D_{1}$}

Michael J. Edel, Cristina Menchon, Sergio Menendez, et al.

Genes Dev. 2010, 24:

Access the most recent version at doi:10.1101/gad.1876710

Supplemental
Material $\quad$ http://genesdev.cshlp.org/content/suppl/2010/03/11/24.6.561.DC1

References This article cites 32 articles, 7 of which can be accessed free at:

http://genesdev.cshlp.org/content/24/6/561.full.html\#ref-list-1

License

Email Alerting Receive free email alerts when new articles cite this article - sign up in the box at the top

Service right corner of the article or click here.

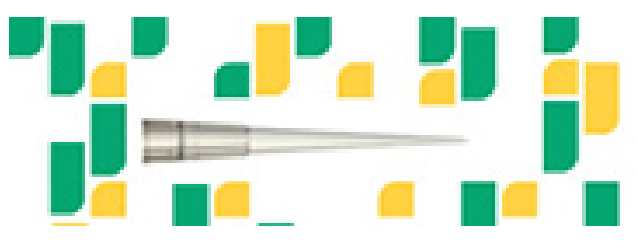

Focused on your science. 